\title{
Fditorial
}

\section{Primary health care for all: lessons from its failure to achieve its goal and COVID-19}

\author{
Erlangga Yusuf \\ Department of Medical Microbiology and Infectious Diseases, \\ Erasmus MC University Medical Center, Rotterdam, the Netherlands
}

According to the World Health Organization (WHO), primary health care (PHC) can be defined as a whole-of-society approach to health and well-being, centered on the needs and preferences of individuals, families and communities. $^{(1)}$ In the last five years, several major events occurred that emphasize the importance of and the need for PHC. First, the publication of the United Nations Sustainable Development Goals (SDGs) in 2015.(2) One of the SDGs is to achieve universal health care (UHC). UHC means that all people can get access to health service without it resulting in financial hardship, and the WHO believes that PHC is fundamental to achieving UHC. . $^{(3)}$ Second, a new international declaration on $\mathrm{PHC}$ has been released in Astana, Kazakhstan, in 2018.(4) This is a new declaration and global commitment on $\mathrm{PHC}$, four decennia after the first declaration on PHC in Alma-Ata, in the former Soviet Union.

Despite the great beginning that culminated in the Alma-Ata declaration, PHC failed to reach the aim of 'health for all by 2000'. In the year 2000 , there was still inequity in the access to health care. ${ }^{(5)}$ Part of this failure can be explained by the rivalry between the PHC and the 'selective' PHC proponents. The 'selective' PHC concept was launched almost immediately after Alma-Ata in 1978. As the word 'selective' implies, selective PHC covered only a narrow package of low-cost technical interventions to tackle the main disease problems of poor countries, for example by the introduction of growth monitoring, oral rehydration, breastfeeding, and immunization program (GOBI). This was the reaction of the 'selective' PHC supporters who considered that the broad PHC was slow, and even impossible to achieve because it was too comprehensive and too optimistic. The division was even more difficult to reconcile since the choice of public health priorities in the 'selective' PHC was done by policy makers (top - down), which was exactly the contrary of what the PHC was aiming, i.e. public participation.

Despite the PHC failure to achieve health for all and the success of GOBI, in the four decades since Alma-Ata, the recognition of the importance of the Declaration's original vision for PHC never really faded. ${ }^{(6)}$ Yet, it is clear that the commitment to PHC from the government is needed more than ever, to make PHC a success. Regarding 'broad' PHC versus 'selective' PHC, it should be realized that broad PHC can go hand in hand with 'selective' PHC because they share many important beliefs. They both consider poverty, deprivation, malnutrition, lack of education, and a gross maldistribution of resources as important problems causing ill health. ${ }^{(7)}$ Similarly, they believe that cheap interventions could prevent many infant, child, and maternal deaths and some other illnesses and deaths. Supporters of 'selective' PHC put too much emphasis on economic aspects and costefficiency while they may forget that holistic approach and putting permanent infrastructure (as strived for in the original version of $\mathrm{PHC}$ ) has 
many other effects that cannot be measured using money and currencies, such as selfempowerment and happiness. It is important to end the discussion and to decide to choose one direction. Broad PHC is indeed ambitious. Therefore, it can be expected that achieving properly functioning $\mathrm{PHC}$ is a long, and painstaking process. Let it grow at its own speed, and accept that the process is more an evolution than a revolution.

At this moment, we are at the dawn of economic recession due to the corona virus disease of 2019 (COVID-19) pandemic. The recession will hit many countries, including developing countries. It is not unthinkable that these countries are going to knock on the door of the International Monetary Fund (IMF) in the future for a loan. In the past, the IMF that is an institutional embodiment of neoliberalism (an idea that is shared by several supporters of 'selective' PHC), requested structural adjustment policies to the countries that needed loans from it. ${ }^{(8)}$ This approach may be counterproductive to the PHC. The neoliberal idea puts emphasis on the minimum influence of governments and is associated with free-market capitalism and often with austerity. Structural adjustment policies required governments to reduce spending, including subsidies and investment in health care. The IMF considered health as a commodity, for which fees should be paid for services. Consequently, access to health care became limited. Many countries have overlooked primary care services and the primary health-care strategy as the vehicle for tackling disease outbreaks. ${ }^{(9)}$

In conclusion, $\mathrm{PHC}$ failed to achieve 'health for all by 2000' but it has led to an unexpected twist with the success of 'selective' PHC. The recent renewal of commitment from many governments of the world on PHC in Astana, Kazakhstan in 2018 is the first important step in reaching UHC. The possible economic impact due to the COVID-19 pandemic may pose a threat to PHC and UHC, and should be anticipated.

\section{REFERENCES}

1. World Health Organization. Primary health care. Geneva: World Health Organization; 2019.

2. Barredo L, Agyepong I, Liu G, Reddy S. Ensure healthy lives and promote well-being for all at all ages. UN Chronicle 2015;51:4. https://doi.org/ 10.18356/3bfe3cfa-en.

3. Van Weel C, Kidd MR. Why strengthening primary health care is essential to achieving universal health coverage. CMAJ 2018; 190:E4636. doi: 10.1503/cmaj.170784.

4. World Health Organization. Declaration on Primary Health Care. Astana: World Health Organization; 2018.

5. Haider W. Why health for all by 2000 policy (HFA 2000) failed to achieve its goal? Ann King Edw Med Univ 2019;25:1-3.

6. World Health Organization Regional Office for Europe. From Alma-Ata to Astana: Primary health care - reflecting on the past, transforming for the future. Copenhagen, Denmark: WHO Regional Office for Europe; 2018.

7. World Health Organization. Why is primary health care important? Geneva: World Health Organization; 2019. https://www.who.int/newsroom/fact-sheets/detail/primary-health-care.

8. Clift B. The IMF and the politics of austerity in the wake of the global financial crisis. Oxford: Oxford University Press; 2018.

9. Rasanathana K, Evans TG. Primary health care, the Declaration of Astana and COVID-19. Bull World Health Organ 2020;98:801-8. doi: http:// dx.doi.org/10.2471/BLT.20.252932. 